\title{
LENTIVÍRUS DE PEQUENOS RUMINANTES EM OVINOS SANTA INÊS: ISOLAMENTO, IDENTIFICAÇÃO PELA PCR E INQUÉRITO SOROLÓGICO NO ESTADO DE PERNAMBUCO
}

\section{L.S.P. da Costa ${ }^{1}$, P.P. de Lima ${ }^{1}$, A.K.C. Callado ${ }^{2}$, S.A. do Nascimento ${ }^{1}$, R.S. de Castro ${ }^{1}$}

${ }^{1}$ Universidade Federal Rural de Pernambuco, Departamento de Medicina Veterinária, Rua Dom Manoel de Medeiros, s/no, CEP 52171-900, Recife, PE, Brasil.

\section{RESUMO}

\begin{abstract}
Os pequenos ruminantes podem ser infectados por um grupo de vírus genericamente denominado de Lentivírus de Pequenos Ruminantes (LVPR), que compreende vários isolados, distribuídos em quatro grupos filogenéticos. Os vírus Maedi-Visna (MVV) e da Artrite Encefalite Caprina (CAEV), originalmente, isolados de ovinos e caprinos, respectivamente, são os protótipos dos dois grupos. O objetivo desse trabalho foi isolar, identificar amostra de LVPR e realizar levantamento sorológico, em ovinos da raça Santa Inês. Através do co-cultivo de células de membrana sinovial ovina e sangue periférico de um ovino soropositivo ao teste de IDGA foi isolado LVPR, amostra BrPe2-01, identificada pelo aparecimento de sincícios nas monocamadas e pela reação em cadeia da polimerase (PCR). A sorologia foi feita através do teste de Imunodifusão em Gel de Agar (IDGA) em animais de 25 propriedades procedentes das regiões Agreste, Sertão, Mata Meridional e Metropolitana do Estado de Pernambuco, totalizando 558 amostras. Os resultados demonstraram sorologia positiva em $6(1,07 \%)$ ovinos de $3(12 \%)$ rebanhos estudados. Concluiu-se que os ovinos da raça Santa Inês estão sendo infectados pelos LVPR, porém com baixa prevalência.
\end{abstract}

PALAVRAS-CHAVE: Maedi-Visna, CAEV, Lentivírus, isolamento, PCR, sorologia.

\section{ABSTRACT}

SMALL RUMINANT LENTIVIRUS INSANTA INÊSOVINES: ISOLATION, IDENTIFICATION BY PCR AND SEROLOGICAL SURVEY IN THE STATE OF PERNAMBUCO, BRAZIL. Small ruminants can be infected by a group generically denominated as small ruminant lentiviruses (SRLV), which comprehend several isolates, distributed into four phylogenetic groups. The Maedi-Visna (MVV) and caprine arthritis encephalitis (CAEV) viruses, originally isolated from ovine and caprine, respectively, are the prototypes of both groups. The objective of this work was to isolate and identify an SRLV strain and carry out a serological survey in ovines of the Santa Inês breed. Through co-cultivation of ovine sinovial cells and leucocytes of a seropositive ewe, LVSR was isolated (BrPe2-01 strain), and identified by the appearance of syncitium on the monolayers and by polymerase chain reaction (PCR). The serology was done through the agar gel immunodiffusion test (AGID) in 558 sheep of 25 flocks from the state of Pernambuco, Brazil. The results demonstrated positive serology in $6(1.07 \%)$ sheep of $3(12 \%)$ studied flocks. It was concluded that the ovine of the Santa Inês breed are being infected by SRLV, with low prevalence.

KEY WORDS: Maedi-Visna, CAEV, lentivirus, isolation, PCR, serology.

\section{INTRODUÇÃO}

Os pequenos ruminantes podem ser infectados por um grupo de vírus genericamente denominado de Lentivírus dePequenos Ruminantes (LVPR), que compreende vários isolados, distribuídos em quatro grupos filogenéticos (SHAH etal., 2004), que compartilham similaridade genética, mecanismo molecular de replicação, morfologia e interação biológica com os hospedeiros. Os protótipos dos dois grupos principais são os vírus Maedi-Visna (MVV) e da Artrite Encefalite Caprina (CAEV), originalmente isolados de ovinos e caprinos, respectivamente (CASTRO et al., 1999a; SHAH et al., 2004).

\footnotetext{
${ }^{2}$ Ministério da Agricultura, Pecuária e Abastecimento, Laboratório Nacional Agropecuário, Recife, PE, Brasil.
} 
A maioria dos pequenos ruminantes infectados com LVPR não desenvolve sinais clínicos, sendo a infecção caracterizada por alta prevalência de animais soropositivos, aparentemente saudáveis. Nos animais afetados, a doença é multissistêmica, progressiva e crônica, as principais manifestações clínicas incluem: pneumonia intersticial, encefalite, artrite, mastite, podendo ser observadas linfadenopatias e emagrecimento progressivo que pode ocorrer de forma isolada ou simultânea (PHelPs; SMITH, 1993). A transmissão dos LVPR ocorre principalmente pela ingestão de colostro e leite de fêmeas infectadas e por via respiratória, mais freqüente em períodos de confinamento. Estudos sugerem que a transmissão vertical deste vírus pode ocorrer em condições naturais, entretanto o mecanismo e a freqüência, não são conhecidos. O sêmen para inseminação artificial e a transferência de embrião representam o menor risco e o risco mínimo para transmissão dos LVPR, respectivamente (BlacKLAWs et al., 2004). Através de estudos filogenéticos recentes tem sido demonstrada a transmissão dos LVPR de ovinos para caprinos e vice versa (Leroux et al., 1997; ZANONI et al., 1998; CASTRO et al., 1999a; SHAH et al., 2004).

Pelas características da infecção persistente por LVPR, a forma mais prática de diagnóstico é a sorologia, pois a presença de anticorpos demonstra indiretamente a existência de infecção. Dentre os testes sorológicos disponíveis, os mais utilizados são a Imunodifusão em Gel de Agar (IDGA) e os ensaios imunoenzimáticos (ELISA) (KNOWLes et al., 1994; AlencAr, 2001). A IDGA é o teste recomendado para certificação internacional para LVPR (OIE, 2004). Por outro lado, a alternativa para detecção dos lentivírus nos estágios iniciais da infecção ou identificação de animais falso negativos, devido à restrição da replicação, éa Reação em Cadeia dePolimerase(PCR). Para isto, têm sido utilizados iniciadores derivados das seqüências dos genes gag ou pol, em PCR ou RTPCR, em amostras de leucócitos, células do leite, lavado brônquio alveolar, líquido sinovial e células obtidas por tripsinização de monocamadas ou explantes (CASTRO et al., 1999b).

Os Lentivírus de Pequenos Ruminantes têm sido notificados em diversos países, com prevalências mais elevadas nos que apresentam a ovinocaprinocultura mais tecnificada (CALLADo etal., 2001). No Brasil vários estudos têm demonstrado alta prevalência dos LVPR em caprinos leiteiros (CUNHA; NAscimento, 1995; SARAiva Neto et al., 1995; CAllado et al., 2003; Silva et al., 2004; LeiTE et al., 2004) e baixa ou nula em animais sem raça definida (SRD) (PINHEIRO, 2001; CASTRO et al., 2002;OliveIra, 2003; Meloetal., 2003). Entretanto, a atual situação da distribuição entre os ovinos está indefinida, pois existem poucos estudos epidemiológicos. Em trabalhos recentes fo- ram observados ovinos soropositivos para LVPR em Pernambuco (Oliveira, 2003), São Paulo (Fernandeset al., 2003) e Ceará (ARAújo et al., 2004); no Piauí e Sergipe, entretanto, não foram encontrados ovinos soropositivos (BATISTA et al., 2004; Meloet al. 2003). No Estado de Pernambuco especificamente, foi encontrada uma freqüência de caprinos soropositivos para LVPR de 17,6\%, em rebanhos de caprinos leiteiros (SARAiva Netoet al.,1995); 15,3\%, em caprinos leiteiros e de corte (CALlADO et al., 2003); e de 3,7\%, em animais SRD de abatedouros. Em ovinos, a freqüência encontrada em animais deslanados SRD, também de abatedouros, foi de 5,2\% (OliveIRA, 2003), porém, não há estudo visando o isolamento de LVPR em ovinos da raça Santa Inês, a principal utilizada para o melhoramento genético de animais deslanados SRD da Região Nordeste, bem como para formação e melhoramento dos rebanhos de outras Regiões (Norte, Centro-Oeste e Sudeste) que progressivamente vem desenvolvendo a ovinocultura.

Considerando a importância dos ovinos da raça Santa Inês para a ovinocultura brasileira, bem como os potenciais efeitos negativos da infecção pelos LVPR sobre a produção, ocusto com o controlee as restrições comerciais, este trabalho foi conduzido com o objetivo de investigar a infecção por LVPR em ovinos Santa Inês, através do isolamento, identificação viral pela PCR e sorodiagnóstico, para inferir sobre os potenciais riscos de disseminação desse vírus entre os rebanhos.

\section{MATERIAL E MÉTODOS}

\section{Isolamento e identificação viral}

Para o isolamento viral foi feito o co-cultivo de células de membrana sinovial ovina (MSO) com leucócitos de sangue periférico de uma ovelha Santa Inês soropositiva, segundo Lima et al. (2004). Os leucócitos foram obtidos coletando-se $10 \mathrm{~mL}$ desangue em tubo tipo vacutainer contendo heparina, através do puncionamento venoso jugular, e armazenados em temperatura de $4^{\circ} \mathrm{C}$ até o processamento. O sangue foi centrifugado a 35,5 g por 30 min em centrífuga clínica, os leucócitos foram cuidadosamente retirados com auxílio de micropipetas e transferidos para tubos de 15 $\mathrm{mL}$. Foram acrescidos $10 \mathrm{~mL}$ de solução à $4^{\circ} \mathrm{C}$ decloreto de amônio a $0,84 \%$, para lise das hemácias; esta suspensão foi homogeneizada e centrifugada a $35,5 \mathrm{~g}$ por 10min em centrífuga clínica. O sobrenadante foi desprezado e os leucócitos ressuspensos em $10 \mathrm{~mL}$ de Solução Salina Fosfatada (PBS) à $4^{\circ} \mathrm{C}(1,32 \mathrm{~g}$ de $\mathrm{Na}_{2} \mathrm{HPO}_{4} ; 0,176 \mathrm{~g}$ de $\mathrm{NaH}_{2} \mathrm{PO}_{4} \cdot \mathrm{H}_{2} \mathrm{O} ; 8,5 \mathrm{gdeNaCl} ; 100$ $\mathrm{mL}$ de $\mathrm{H}_{2} \mathrm{O}$ ), homogeneizados e centrifugados a 35,5 $\mathrm{g}$ por $10 \mathrm{~min}$. Este procedimento foi repetido duas vezes, 
sempre desprezando-se o sobrenadante. Os leucócitos assim obtidos foram ressuspensos em $10 \mathrm{~mL}$ de meio RPMI a $37^{\circ} \mathrm{C}$ acrescido de $250 \mathrm{UI} / \mathrm{mL}$ de Penicilina G potássica e $100 \mu \mathrm{g} / \mathrm{mL}$ de Estreptomicina, homogeneizados e acrescido soro fetal bovino até a concentração final de $10 \%$. Todo o conteúdo foi transferido para uma garrafa de cultivo celular de $25 \mathrm{~cm}^{2}$ de área de cultivo, colocada em estufa a $37^{\circ} \mathrm{C}$ e incubada por uma semana. Após 24 h de cultivo, o meio RPMI foi substituído para retirar o excesso de células em suspensão.

Para oco-cultivo dosleucócitos, células demembrana sinovial ovina (MSO) foram obtidas a partir de membrana sinovial de fetos ovinos soronegativos e mães sorologicamente negativas a IDGA para LVPR, de acordo com Abreu et al. (1998). O sobrenadante do cultivo de leucócitos foi desprezado e a garrafa foi lavada por três vezes com PBS a $37^{\circ} \mathrm{C}$. Às garrafas foram acrescentadas células de MSO, na concentração de $3 \times 10^{4}$ células $/ \mathrm{cm}^{2}$ em meio MEM com $250 \mathrm{UI} / \mathrm{mL}$ de Penicilina G potássica e $100 \mu \mathrm{g} / \mathrm{mL}$ de Estreptomicina, e 5\% de soro fetal bovino (meio de manutenção celular). As garrafas foram incubadas a $37^{\circ} \mathrm{C}$ e examinadas freqüentemente ao microscópio ótico, para verificaçãodosurgimentodeefeitocitopático (ECP), caracterizado pela formação de sincícios. Após 10 dias de cultivo, o sobrenadante foi coletado, armazenado a $-20^{\circ} \mathrm{C}$, e foi acrescentado novo meio de manutenção celular. Após o aparecimento de ECP a monocamada foi tripsinizada e ampliada na proporção de 1:2. Quando da formação denova monocamada uma das garrafas foi corada com cristal violeta a $0,1 \%$ e examinada ao microscópio ótico.

A identificação da amostra isolada foi feita pela reação em cadeia da polimerase (PCR) usando-se leucócitos sanguíneos e células do co-cultivo. A extração do DNA foi feita com a alíquota retirada dos leucócitos de sangue periférico através do Kit de Extração GFX ${ }^{T M}$ Genomic Blood DNA Purification Kit (Amersham Biosciences), segundo instruções do fabricante e armazenada a $-80^{\circ} \mathrm{C}$. Além disso, amostras de DNA foram preparadas a partir da suspensão celular obtida por tripsinização da monocamada (CAstro, 1998). Os DNAs obtidos foram usados para amplificação de um fragmento de $475 \mathrm{nt}$ do gene pol de LVPR, correspondente a uma região conservada do gene pol, empregando-se iniciadores degenerados (Leroux et al., 1995) (Tabela 1), nas condições previamente descritas (CASTRO, 1998).

\section{Rebanhos e animais}

A pesquisa de anticorpos anti-LVPR em ovinos, foi realizada no período de 2003 a 2004, envolvendo 25 rebanhos (R) localizados nas Regiões Agreste (12 R), Sertão (5R), Mata Meridional Pernambucana (4R) e Metropolitana (4R). As criações foram selecionadas usando-se o seguinte critério: criar ovinos Santa Inês puros e ter a concordância do proprietário.

Em cada rebanho foram colhidas amostras de pelo menos 20 ovinos, sendo: 14 matrizes, 5 machos ou fêmeas pré-púberes, com mais de 6 meses de idade, e 1 reprodutor, totalizand 558 amostras de soros de ovinos, sendo 36 reprodutores, 425 matrizes e 97 animais não púberes, com mais de 6 meses.

\section{Teste Sorológico}

O teste sorológico empregado foi a IDGA, utilizando-se antígeno da amostra Cork de LVPR e soro padrão positivo, produzidos e padronizados conforme ABreu et al. (1998).

\section{RESULTADOS E DISCUSSÃO}

A partir de uma ovelha do R 14 foi isolada uma amostra de LVPR (denominada BrPe2-01) em cultivo celular, identificada preliminarmente pelo aparecimento de ECP, caracterizado por poucos sincícios na monocamada, observados 12 dias após adição de células de MSO aos leucócitos do animal. Após passagens em cultivo celular a amostra BrPe2-01 se mostrou inicialmente pouco lítica. Entretanto, após 3 meses de cultivo causou a destruição da monocamada. A confirmação do isolamento foi feita pela amplificação, através da PCR, de um fragmento de 475 nt do gene $p o l$, com base na seqüência do Maedi-Visna (Leroux et al., 1995) (Fig. 1).

Tabela 1 - Oligonucleotídeos iniciadores usados nas PCR para amplificação dos genes pol de LVPR.

\begin{tabular}{lllc}
\hline & Oligonucleotídeo iniciador & \\
\hline${\text { Gene } p l^{\mathrm{b}}}$ & Nome & Seqüência $\left(5^{\prime} \rightarrow 3^{\prime}\right)^{\mathrm{a}}$ & Posição (Visna-Maedi K1514) \\
& P1 & DSAAGARAAATTARARGG & $2198-2215$ \\
& P2 & ATCATCCATRTATATBCCAAATTG & $2672-2650$ \\
\hline
\end{tabular}

${ }^{\mathrm{a} B}=\mathrm{C}, \mathrm{G}$ ou $\mathrm{T} ; \mathrm{D}=\mathrm{A}, \mathrm{G}$ ou T; R = A ou G; $=\mathrm{C}$ ou $\mathrm{G} ; \mathrm{M}=\mathrm{A}$ ou $\mathrm{C} ; \mathrm{Y}=\mathrm{C}$ ou $\mathrm{T}$

bSegundo Leroux et al. 1995. 


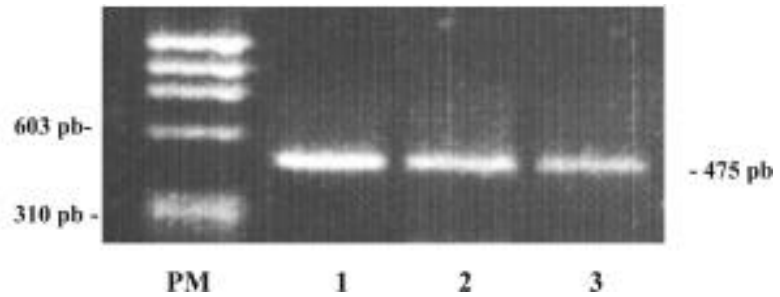

Fig. 1 - PCR da região pol de LVPR. Oligonucleotídeos iniciadores P1/P2. (PM) $\phi X 174$ HaeIII, (1) Maedi-Visna K 1514, (2) BrPe2-01 - co-cultivo celular, (3) BrPe2-01 leucócitos sangüineos.

Os achados do isolamento viral (tipo de ECP, tempo atéo surgimento e destruição da monocamada) em linhas gerais foram compatíveis com outros relatos de isolamento de amostras líticas de LVPR (NARAYAN et al., 1980; ChEBLOUNE et al., 1996; MARCHESIN et al., 1997; CASTRO et al., 1998; LiMA, 2004).

Do total de amostras de soro testadas, $6(1,07 \%)$ foram positivas à IDGA para pesquisa de anticorpos anti-LVPR, pertencentes a animais de $3(12 \%)$ criações estudadas. A distribuição de freqüência de animais soropositivos nos rebanho foi de 5,0\% (R-15 e R21) e $11,1 \%$ (R-14) (Tabela 2). Em linhas gerais, a freqüência de animais soropositivos observadas neste trabalho se assemelha à registrada para ovinos Santa Inês do Estado de São Paulo (FernANDEs et al., 2003). Entretanto, éinferior às observadas em animais puros de outras raças também deSão Paulo(FERNANDES et al., 2003), bem como em ovinos deslanados SRD de Pernambuco (Oliveira et al., 2003) e Ceará (Araújo et al., 2004). Embora quantitativamente baixa, esta freqüência deve ser considerada importante, já que se trata de animais deraça especializada, que está sendo acometida pelos LVPR e pode disseminar esse agente para os ovinos deslanados SRD, principal contingente ovino do Nordeste brasileiro, considerados negativos (BATISTA et al., 2004) ou infectados com baixa prevalência (Oliveira et al., 2003; Araújo et al., 2004), bem como nas criações em formação, principalmente, nas Regiões Norte, Centro-Oeste e Sudeste.

Algumas características dos animais positivos e dos respectivos rebanhos de origem que podem ser úteis na tentativa de explicar a origem da infecção merecem destaque: os animais do R-14 são criados de forma extensiva, juntamente com caprinos, inclusive com histórico de soropositividade para LVPR, ondeé prática corrente o uso do soro de leite desta última espécie, como complemento alimentar para os ovinos; no R-15, os animais são criados de forma semi-extensiva, soltos no pasto juntamente com caprinos; no R19, havia cabras leiteiras que forneciam leite para alimentação dos borregos. É conhecido que o colostro e o leite são as principais fontes de infecção para caprinos e ovinos (BLACKLAWset al., 2004). Embora não
Tabela 2- Distribuição da freqüência de ovinos Santa Inês testados para Lentivírus de Pequenos Ruminantes, através do teste de imunodifusão em gel de Agar (IDGA) de acordo com o rebanho (R) e o Município do Estado de Pernambuco. Recife, 2005.

\begin{tabular}{|c|c|c|c|}
\hline \multirow[t]{2}{*}{ Região/Municípios } & \multicolumn{2}{|c|}{ Resutado da IDGA } & \multirow[t]{2}{*}{ Total } \\
\hline & $\begin{array}{l}\text { № posi- } \\
\text { tivo }(\%)\end{array}$ & $\begin{array}{l}\text { № nega- } \\
\text { tivo (\%) }\end{array}$ & \\
\hline \multicolumn{4}{|l|}{ Metropolitana } \\
\hline R-1 Aldeia & $0(0,0)$ & $22(100,0)$ & 22 \\
\hline R-2 Curado & $0(0,0)$ & $20(100,0)$ & 20 \\
\hline R-3 Moreno & $0(0,0)$ & $20(100,0)$ & 20 \\
\hline R-4 Tiúma & $0(0,0)$ & $18(100,0)$ & 18 \\
\hline \multicolumn{4}{|l|}{ Mata Meridional } \\
\hline R-5 Paudalho & $0(0,0)$ & $24(100,0)$ & 24 \\
\hline R-6 Paudalho & $0(0,0)$ & $21(100,0)$ & 21 \\
\hline R-7 Lagoa do Carro & $0(0,0)$ & $20(100,0)$ & 20 \\
\hline R-8 Timbaúba & $0(0,0)$ & $30(100,0)$ & 30 \\
\hline \multicolumn{4}{|l|}{ Agreste } \\
\hline R-9 Alagoinha & $0(0,0)$ & $20(100,0)$ & 20 \\
\hline R-10 Camocim de S. Félix & $0(0,0)$ & $21(100,0)$ & 21 \\
\hline R-11 Brejo M. de Deus & $0(0,0)$ & $31(100,0)$ & 31 \\
\hline R-12 Riacho das Almas & $0(0,0)$ & $20(100,0)$ & 20 \\
\hline R-13 Serra Negra & $0(0,0)$ & $21(100,0)$ & 21 \\
\hline R-14 Pedra & $4(11,1)$ & $32(88,9)$ & 36 \\
\hline R-15 Pesqueira & $1(5,0)$ & $19(95,0)$ & 20 \\
\hline R-16 Gravatá & $0(0,0)$ & $20(100,0)$ & 20 \\
\hline R-17 Gravatá & $0(0,0)$ & $20(100,0)$ & 20 \\
\hline R-18 Gravatá & $0(0,0)$ & $20(100,0)$ & 20 \\
\hline R-19 Gravatá & $0(0,0)$ & $20(100,0)$ & 20 \\
\hline R-20 Venturosa & $0(0,0)$ & $34(100,0)$ & 34 \\
\hline \multicolumn{4}{|l|}{ Sertão } \\
\hline R-21 São José do Egito & $1(5,0)$ & $19(95,0)$ & 20 \\
\hline R-22 São José do Egito & $0(0,0)$ & $20(100,0)$ & 20 \\
\hline R-23 São José do Egito & $0(0,0)$ & $20(100,0)$ & 20 \\
\hline R-24 São José do Egito & $0(0,0)$ & $20(100,0)$ & 20 \\
\hline R-25 Sertânia & $0(0,0)$ & $20(100,0)$ & 20 \\
\hline Total & $6(1,1)$ & $552(98,9)$ & 558 \\
\hline
\end{tabular}

seja possível afirmar categoricamente, deve-se considerar, neste estudo, o uso de leite caprino ou seu derivado, como suplemento para alimentação de ovinos, como potencial fonte de infecção, pois como foi demonstrado experimentalmente (BANKset al.,1983) e em estudos filogenéticos recentes (Leroux et al., 1997; ZANONi et al., 1998; SHAH et al., 2004) há transmissão natural de LVPR entre essas espécies. É necessário seqüenciar amostras virais isoladas de caprinos do $\mathrm{R}$ 14 e conduzir uma análise filogenética para estabelecer a possível origem da infecção dos ovinos.

Em rebanhos consorciados, uma vez estabelecida a infecção entre as ovelhas, a partir de caprinos, os LVPR poderiam ser transmitidos aos descendentes 
através do colostro ou leite. Além disso, a tendência a intensificar o sistema de criação à medida que se busca aumentar a produtividade poderá propiciar condições para a rápida disseminação do vírus, assumindo a transmissão horizontal papel importante, como tem sido observado nos países onde os ovinos são criados em regime de confinamento. Considerando a possibilidade de transmissão dos LVPR entre caprinos e ovinos é imperativo que nas medidas preconizadas nos programas de controle dessas lentiviroses, ambas espécies sejam, do ponto de vista prático, potencialmente consideradas fonte de infecção. Atenção especial deve ser dada à exposição aos caprinos leiteiros, devido a alta prevalência de LVPR observada neste tipo de animal (CUNHA; NASCIMENTO, 1995; SARAiva Neto, et al., 1995; CALlado et al., 2003; Silva et al., 2004; LeITE et al., 2004).

Ao exame clínico o animal infectado apresentavase aparentemente saudável, chamando a atenção apenas uma ligeira assimetria entre as duas metades da glândula mamária. A ausência de histórico clínico nos outros animais soropositivos, compatíveis com a infecção por LVPR, mesmo no R 14 que apresentou a freqüência mais elevada, pode indicar que a amostra BrPe2-01 é pouco indutora de lesões de LVPR. Alternativamente, o manejo extensivo ou semi-extensivo usados nos rebanhos, possivelmente contribuiu para a redução da incidência de alterações detectáveis ao exame clínico geral.

Com base nos resultados obtidos neste estudo conclui-se que: a infecção por LVPR está pouco difundida nas criações de ovinos da raça Santa Inês estudadas em Pernambuco; considerando-sequenos rebanhosonde foram identificados animais positivos a criação é conjunta com caprinos e que é usado leite de cabra ou lactosoro na alimentação dos ovinos, levanta-se a hipótese da transmissão natural entre essas espécies; a amostra BrPe2-01, identificada pela PCR como LVPR e classificada como pouco lítica em cultivo celular, parece ser pouco indutora de alterações clínicas.

\section{AGRADECIMENTOS}

Ao Conselho Nacional de Desenvolvimento Científico e Tecnológico-CNPq, pelo financiamento do presente trabalho.

\section{REFERÊNCIAS}

Abreu, S.R.O.; Castro, R.S.; Nascimento, S.A.; Souza, M.G. Produção de antígeno nucleoproteíco do vírus da Artrite-Encefalite Caprina e comparação com o do vírus Maedi-Visna para utilização em teste de imunodifusão em ágar gel. Pesquisa Veterinária Brasileira, v.18, n.2, p.57-60, 1998.
Alencar, C.A.S.Padronização deensaios imunoenzimáticos (LABELISA e Elisa-i) para detecção de anticorpos anti-lentivirus de pequenos ruminantes em ovinos. 2001. 21f. Dissertação (Mestrado em Ciências Veterinárias) - Universidade Federal Rural de Pernambuco, Recife, 2001.

ARÁUJO, S.A.C.;D ANTAS, T.V.M.;TEIXEIRA,M.F.S.;S ILVA,J.B.A.; Ribeiro, A.L.;SouzA, A.C.F.R. Levantamento sorológico de Maedi-Visna em ovinos de abatedouros da Região Metropolitana de Fortaleza-CE. In: CONGRESSO BRASILEIRODEMEDICINA VETERINÁRIA, 31., 2004, São Luís, MA. Resumos. São Luís, 2004. [CD-ROM].

BANKs, K.; AdAms, D.S.;McGuIRE, T.C.; CARLSON,J. Experimental infection of sheep by caprine arthritis-encephalitis virus and goats by progressive pneumonia. American Journal Veterinary Resarch, v.44, p.2307-2311, 1983.

Batista, M.C.S.; C astro, R.S.; C arvalho, F.A.A.; C RUZ, M.S.P.; RêGo, E.W.; Silva, S.M.M.S.; Oliveira, R.A.; LOPES, J.B. Pesquisa de anticorpos anti-lentivírus de pequenos ruminantes em ovinos, no Estado do Piauí, Brasil. In: CONGRESSO BRASILEIRO DE MEDICINA VETERINÁRIA, 31., 2004, São Luís, MA. Resumos. São Luís, 2004. [CD-ROM].

Blacklaus, B.A.; Berriatua, E.; Torsteinsdottir, S.; W att N.J.; DEANDRÉs, D.; K LEIN, D.; H ARKISS, G.D. Transmission of small ruminant lentiviruses. Veterinary Microbiology, v.101, n.3, p199-208, 2004.

CAllado, A.K.C.; C ASTRO, R.S.; T eixeIRA, M.F.S. Lentivírus de pequenos ruminantes (CAEV e Maedi-Visna). Revisão e perspectiva. Pesquisa Veterinária Brasileira, v.21, n.3, p.87-97, 2001.

Callado, A.K.C.; Falcão, L.S.P.C.A.; Castro, R.S.; Oliveira, E.J.C.; FalCÃo FILHO, M.C.A.; ARrUdA, E.T.Levantamento sorológico para CAEV em caprinos do Estado de Pernambuco.In:CONGRESSOLATINOAMERICANO DE BUIATRIA, 11., 2003, Salvador, BA. Resumos.Salvador, 2003. p.50.

CASTRO, R.S. Lentivirus de pequenos ruminantes: ensaios imunoenzimáticos, perfil sorológicoeinfluênciafilogenéticas. 1998. 132 f. Tese (Doutorado) - Escola de Veterinária, Universidade Federal de Minas Gerais. Belo Horizonte, 1998.

Castro, R.S.; Greenland, T.; Leite, R.C.; Gouveia, A.; Mornex, J-F.; C ORDIER, G. Concerved sequence motifs involving the tat reading frame of Brazilian caprine lentiviruses indicate affiliations to both caprine arthritisencephalitis virus and visna - maedi virus. Journal General Virology, v.80, p.1583-1589, 1999a.

Castro, R.S.; Azevedo,E.O.; T abosa, I.; Nascimento, S.A.;O liveiRA, M.M.M. Anticorpos para o vírus da Artrite encefalite caprina em animais sem raça definida de abatedouros dos Estados de Pernambuco e Paraíba. Ciência Veterinária nos Trópicos, v.5, n.2/3, p.121-123, 2002.

Castro, R.S.; Leite, R.S.; Resende, M.; Martins, A.; Gouveia, A.M.G. Caprine Arthritis encephalitis vírus isolation and identification using fluorescent antibody and polymerase chain reaction. Arquivo Brasileiro de $\mathrm{Me}$ dicina Veterináriae Zootecnia, v.51, n.3, p.235-240,1999b.

Chebloune, Y.; Karr, B.; Sheffer, D.; Leung, K.; Narayan, O. Variations in lentiviral gene expression in monocytederived macrophages from naturally infected sheep. Journal General Virology, v.77, p.2037-2051, 1996. 
Cunha, R.G.; Nascimento, M.D. Ocorrência de anticorpos para o vírus da artrite-encefalite caprina em soros de caprinos do Estado do Rio de Janeiro. Revista Brasileira de Medicina Veterinária, v.17, p.72-75, 1995.

Fernandes, M.A.; Araújo, W.P.; Castro, R.S. Prevalência da infecção pelo vírus Maedi-Visna em ovinos da microregião grande São Paulo, Estado de São Paulo. Ciência Veterinária nos Trópicos, v.6, n.1, p.23-28, 2003.

Knowles, D.P.; Evermann Junior, J.F.; Shropshire, C.; Vanderschalie, J.; Bradway, D.; Gezon, H.M.; Cheevers, W.P.Evaluation of agargelimmunodiffusionserology using caprine and ovine lentiviral antigens for detection of antibody to caprine arthritis-encephalitis virus. Journal Clinical Microbiology, v.32, p.243-245, 1994.

LeITE, B.L.S.;Modolo,J.R.;P adOVAnI, C.R.;S TACHISSINI, A.V.M.; CASTRO, R.S. DE; SimÕes L.B. Avaliação da taxa de ocorrência da artrite encefalite caprina a vírus pelas regionais do Escritório de Defesa Agropecuária do Estado de São Paulo, Brasil e seu mapeamento por meio de informações geográfica. Arquivos do Instituto Biológico, São Paulo, v.71, n.1, p.21-26, 2004. Disponível em: <http://www.biologico.sp.gov.br/ARQUIVOS/ V71_1/leite.pdf>. Acesso em: 16 abr. 2005.

Leroux, C.; Vuillermoz, S.; Mornex, J.-F.; Greenland, T. Genomic heterogeneity in the pol region of ovine lentivirus obtained from bronchoalveolar cells of infected sheep from France. Journal General Virology, v.76, p.1533-1537, 1995.

Leroux, C.; C hastang, J.; Greeland, T.;Mornex, J.F.Genomic heterogeneit of small ruminant lentiviruses: existence of heterogeneous populations in sheep and of the same lentiviral genotypes in sheep and goats. Archives of Virology, v.142, p.1125-1137, 1997.

Lima, P.P.; Rocha, M.A.; Stancek, D.; Gouveia, A.M,G.; Oliveira, G.D.R. Vírus da Artrite Encefalite Caprina: Isolamento e Caracterização Parcial do Gene gag. Arquivo Brasileiro de Medicina Veterinária e Zootecnia, v.56, n.2, p.135-142, 2004.

Marchesin, D.M.; Moojen, V.; Ravazzolo, A.P. Caracterização molecular do gene gag de amostras do vírus da artrite-encafalite caprina (CAEV) isoladas de animais naturalmente infectados no Rio Grande doSul, Brasil. Pesquisa Veterinária Brasileira, v.18, p.119-126, 1997.

Melo, C.B.; Castro, R.S.;Oliveira, A.A.; Fontes, L.B.;Callado, A.K.C.; Nascimento, S.A. Estudo Preliminar sobre a Infecção por Lentivírus de Pequenos ruminantes em Ovinos e caprinos de Sergipe. In: CONGRESSO LATINOAMERICANO DE BUIATRIA, 11., Salvador, BA. Resumos. Salvador, 2003. p. 47-48.
Narayan, O.; Glements, J.E.; Strandberg, J.D.; Cork, L.C.; GRIFFIN, D.E. Biological characterization of virus causing leukoencephalitis and arthritis in goats. Journal General Virology, v.50, p.69-79, 1980.

OIE - World Organization for Animal Health.Manual of diagnostic tests and vaccines for terrestrial animals 2004. 5ed. Web version. Paris, 2004. 2v. Disponível em: 〈http://www.oie.int>. Acesso em: 16 abr. 2005.

Oliveira, M.M.M.; Castro, R.S.; Carneiro, K.L.; Nascimento, S.A.;C allado, A.K.C.; A lencar, C.A.;F alCão, L.S.P.C.A. Anticorpos contra Lentivírus de Pequenos Ruminantes (LVPR) em caprinos e ovinos sem raça definida (SRD) e ovinos crioulos em abatedouros no Estado de Pernambuco. In: CONGRESSO LATINO AMERICANO DE BUIATRIA, 11., 2003, Salvador , BA. Resumos . Salvador, 2003. p.1663-1666,1993.

Phelps, S.L.; SMith, M.C. Caprine arthritis encephalitis virus infection. Journal of the American Veterinary Medical Association, v.203, p.1663-1666, 1993.

Pinheiro, R.R. Vírus da Artrite encefalite caprina: Desenvolvimento e padronização de ensaios imunoenzimáticos (ELISA e Dot- blot) e estudo epidemiológico no Estado do Ceará. 2001. 115f. Tese (Doutorado) - Escola de Veterinária, Universidade Federal de Minas Gerais, Belo Horizonte, 2001.

Saraiva Neto, A.O.; Castro, R.S.; Birgel, E.H.; Nascimento, S.A. Estudo soro-epidemiológico da artrite-encefalite caprina em Pernambuco. Pesquisa Veterinária Brasileira, v.15, p.121-124, 1995.

SHAH, C.;HUDER, J.B.; BO“NII,J.;SCHO"NMANN, M.;Mu“HLHERR, J.; Lutz, H.; Schu“PBach, J. Phylogenetic analysis and reclassification of caprineand ovinelentiviruses based on 104 new isolates: evidence for regular sheep-togoat transmission and world propagation through liverstock trade. Virology, v.319, p.12-26, 2004.

Silva, J.B.A.; SOUZA , C.H.; ARAúJO, S.A.C.; DanTas, T.V.M.; TeixeIra, M.F.S.; RIBEIRO, A.L.;SouZA, A.C.F.R.; CASTRO, R.S. Artrite encefalite caprina em matrizes no município de Afonso Bezerra, RioGrande do Norte. In: CONGRESSO BRASILEIRO DE MEDICINA VETERINÁRIA, 31.,2004, São Luís, MA. Resumos. São Luís, 2004. p.14.

ZANONI, R.G.; K RIEG, A.; Peterhans, E.Phylogeneticanalysis of small ruminant lentiviruses. Journal General Virology, v.79, p.1951-1961, 1998.

Recebi em 19/7/06 Aceito em 7/11/06 